\title{
Desafios à geração de trabalho e renda em grupos comunitários de base local
}

\author{
Heloisa Maria Mello Manso*
}

Resumo: $O$ acompanhamento sistemático que realizamos de grupos comunitários de geração de trabalho e renda, localizados em áreas de carência financeira, mostrou-nos que essas iniciativas podem ser melhor compreendidas e potencializadas a partir de orientações teóricas, filosóficas e metodológicas presentes na literatura sobre empreendedorismo social e economia solidária. Os desafios enfrentados pelos grupos comunitários são muitos, devido às suas características culturais e sociais. No entanto, apresentam potencial para formar pessoas empreendedoras, necessidade premente em um contexto societário de desemprego e diminuição da oferta de postos de trabalho. Esses grupos necessitam de apoio material e de orientações político-pedagógicas especiais para que alcancem êxito em seus empreendimentos, diminuam a exclusão social e impulsionem a formação de cooperativas.

Palavras-chave: empreendimentos, economia solidária, grupos comunitários, apoio financeiro/pedagógico.

The challenges of creating jobs and earning opportunities in communitarian groups

Abstract: The systematic and continuous examination of communitarian groups of work output localized in financial deprived regions shows that their initiatives can be better understood and

* Assistente social, mestre em Sociologia pela Universidade Federal de Minas Gerais (UFMG), professora assistente III da Escola de Serviço Social, da Pontifícia Universidade Católica (PUC-Minas). E-mail: hmanso@brfree.com.br 
improved by technical and philosophical orientations present in the literature about entrepreneurships and solidarity economics. Theses communitarian groups face many challenges, because of their cultural and social features. But they present a significant potential to form entrepreneurs, and this is an important measure to fight unemployment and the economic tendency of lacking jobs. These groups need political, material and consulting support based on the principles of solidarity economics to have success in their initiatives, with the reduction of the social exclusion and drawing people to form cooperatives,

Keywords: entrepreneurships, solidarity economics, communitarian groups, financial/consulting supporting.

\section{Introdução}

Em áreas residenciais habitadas por famílias de baixa renda encontramos com freqüência grupos voltados para a geração de trabalho e renda vinculados às associações de moradores, Igrejas, organizações filantrópicas de assistência social e a outras entidades. Alguns manifestam o desejo de se transformarem em cooperativa. Conhecemos vários desses grupos, em nosso trabalho de intervenção social, ocorrido no período de 1986 a 2006, ligado à Pró-Reitoria de Extensão da PUC-Minas, Coração Eucarístico, em Belo Horizonte. Acompanhamos especialmente dois, situados na Boa Vista e no Fundo da Colina - região da Cabana do Pai Tomás, Belo Horizonte - e outros dois no Conjunto Habitacional Darcy Ribeiro e na Vila Esperança - região de Nova Contagem, município de Contagem (MG).

As regiões Cabana e Nova Contagem apresentam grande adensamento populacional e convivem com o desemprego e a violência urbana conseqüente de disputas entre facções envolvidas no tráfico de drogas. São áreas habitadas por famílias de baixo poder aquisitivo, contam com reduzidas 
oportunidades de trabalho e poucos equipamentos de lazer, esporte e cultura. Os serviços de saúde e educação nesses locais são precários, apesar de certas melhorias alcançadas por essas políticas públicas.

As regiões mencionadas vivenciam situações de exclusão que, no dizer do escritor português Amaro (2000, p. 2), afetam seis dimensões principais do cotidiano das pessoas, quais sejam:

- do ser, ou seja, da personalidade, da dignidade e da auto-estima e auto-reconhecimento individual;

- do estar, ou seja, das redes de pertença social, desde a família às redes de vizinhança, aos grupos de convívio e de interacção social e à sociedade mais geral;

- do fazer, ou seja, das tarefas realizadas e socialmente reconhecidas, quer sob a forma de emprego remunerado [...], quer sob a forma de trabalho voluntário não remunerado;

- do criar, ou seja, da capacidade de empreender, de assumir iniciativas, de definir e concretizar projectos, de inventar e criar acções, quaisquer que elas sejam;

- do saber, ou seja, do acesso à informação (escolar ou não, formal ou informal), necessária à tomada fundamentada de decisões, e da capacidade crítica em face da sociedade e do ambiente envolvente;

- do ter, ou seja, do rendimento, do poder de compra, do acesso a níveis de consumo médios da sociedade [...].

Vários moradores de "áreas de carências" procuram superar as situações de exclusão, quando ingressam em programas de Educação de Jovens e Adultos (EJA) - cursos de suplência, pré-vestibular comunitário e em outros programas socioassistenciais disponíveis próximo à residência. Há, também, nessas áreas, uma riqueza de grupos e lideranças 
que se reúnem em prol do bem-estar comunitário, e chama a atenção a consciência de vida coletiva apurada que apresentam, pois envolve preocupação e responsabilidade em relação ao meio ambiente, à própria família e às outras famílias do lugar. São pessoas com visão ampla dos problemas sociais, pois não dissociam renda do cuidado com saúde orgânica e mental, educação, meio ambiente, transporte e emprego.

Organizar grupos para gerar trabalho e renda é um pensamento que circula, comumente, nessas áreas. Pretendemos, com este artigo, mostrar as características e possibilidades de os grupos formarem empreendedores e protagonistas de suas histórias, como também os limites e desafios que apresentam para se transformarem em cooperativas. As considerações que fazemos resultam das observações realizadas in loco, provenientes dos "diários de campo".

\section{Geração de trabalho e renda como empreendimentos sociais solidários, visando à inclusão}

As últimas décadas não foram marcadas pela inserção de trabalhadores no mercado de trabalho. Pelo contrário, explicitaram uma crise relativa ao emprego formal. Vários autores, entre eles Antunes (1995) e Dupas (1999), descrevem intensas e velozes mudanças no mundo do trabalho, a partir da década de 1980, as quais causaram impactos macroeconômicos, desemprego e situações de exclusão social. Para enfrentar as repercussões microssociais desses problemas, emergiram programas, projetos e propostas de ações de cunho coletivo e solidário, provenientes tanto de setores populares quanto de órgãos governamentais.

Recente documento do Ministério de Desenvolvimento Social e Combate à Fome, faz uma listagem das ações 
desenvolvidas pelo Governo Federal, voltadas para a geração de trabalho e renda. Patrus Ananias, por estar à frente deste Ministério, apresenta o documento citado, e escreve que:

Investir no desenvolvimento local para as famílias pobres é urgente, trabalhando com a Educação Cidadã, a Economia Solidária e a Inclusão Produtiva, estimulando o empreendedorismo solidário, em conjunto com os demais órgãos de governo, nos seus três níveis, federal, estadual, municipal, bem como com as empresas brasileiras que, a cada dia, se dedicam mais à Responsabilidade Social e com os movimentos sociais que possuem redes de solidariedade, cuja energia básica é a constante divulgação de conhecimento e troca de experiências. (Brasil. MDS, 2007, p. 4).

Também relacionada ao Governo, mas subordinada ao Ministério do Trabalho e Emprego, foi criada em 2003, a Secretaria Nacional de Economia Solidária (Senaes) para acompanhar e fazer avançar a política da economia solidária, com a missão de: 1) identificar potencialidades, dificuldades, desafios, estratégias, prioridades de ação; 2) fortalecer empreendimentos e atores; 3) comprometer governos e definir parâmetros legais, etc. Foram influentes na criação da Senaes, Paul Singer e Euclides Mance, ambos estudiosos do tema Economia Solidária.

Singer (2005), em seus escritos, argumenta que a natureza da economia solidária não se coaduna com a "cultura capitalista". Ao analisar os casos de agricultores familiares, artesãos e de outros trabalhadores possuidores de seus próprios meios de produção, esclarece que a forma organizativa desses grupos não se confunde com as grandes organizações capitalistas, como os oligopólios e monopólios; antes, antepõem-se a elas.

A competição capitalista, diz Singer (2005, p.14), forma "uma classe cada vez mais numerosa de perdedores, qual 
seja, de pessoas que não têm meios próprios de produção e que se sustentam vendendo sua capacidade de trabalho aos capitalistas (ou ao Estado)". Singer também destaca as relações autoritárias e antagônicas da empresa capitalista, direcionadas para maximizar o lucro, a partir dos esforços dos trabalhadores que ficam limitados ao cumprimento de tarefas, e excluídos dos resultados da firma, sejam positivos (lucros) ou negativos (prejuízos); já na economia solidária, todos têm o mesmo direito de decisão, cada trabalhador é responsável pelas sobras (lucros) e prejuízos, e não há uma classe que viva apenas de rendimentos do capital, sem tomar parte no destino da empresa.

A solidariedade na economia se baseia na associação entre iguais para produzir, comercializar, consumir ou poupar, e Euclides Mance (2006), ao listar as várias manifestações desse tipo de economia, classifica-as em: empresas recuperadas de autogestão (grupo A); associações e cooperativas em transição (grupo B); redes e cooperativas consolidadas (grupo C) e grupos informais de mulheres, jovens e portadores de habilidades especiais (grupos específicos).

Conforme Mance (2006), para fortalecer o movimento da Economia Solidária, há necessidade de: 1) potencializar suas instâncias organizativas, para torná-lo cada vez mais capilarizado; 2) construir cadeias solidárias de produção, comercialização, consumo e finanças; 3) estimular a pedagogia de consumo ético e de repúdio aos processos em que há exploração do trabalho; 4) criar agências de fomento e assistência técnica e adotar marcas e selos de certificação. Além disso, Mance propõe a inclusão da matéria Economia Solidária nos currículos escolares, com uso de livros didáticos específicos, formação de professores, pesquisa, projetos de extensão e apresentação de experiências de empreendimentos - tudo isso, visando ao empoderamento da população. 
A proposta referente ao "empreendedorismo social" é abordada em cursos de Administração de Empresas, ao lado de estudos sobre o "empreendedorismo privado", próprio da cultura capitalista competitiva (Quadro 1). Melo Neto e Froes (2002) descrevem as diferenças fundamentais entre "empreendedorismo privado" e "social".

\section{Quadro 1 - Características do empreendimento}

\begin{tabular}{|l|l|}
\hline Empreendedorismo privado & \multicolumn{1}{|c|}{ Empreendedorismo social } \\
\hline Individual & Coletivo \\
\hline $\begin{array}{l}\text { Produz bens e serviços para o } \\
\text { mercado }\end{array}$ & $\begin{array}{l}\text { Produz bens e serviços para a co- } \\
\text { munidade }\end{array}$ \\
\hline Foco no mercado & $\begin{array}{l}\text { Foco na busca de soluções para } \\
\text { os problemas sociais }\end{array}$ \\
\hline $\begin{array}{l}\text { Lucro é medida de desem- } \\
\text { penho }\end{array}$ & $\begin{array}{l}\text { Impacto Social é medida de des- } \\
\text { empenho }\end{array}$ \\
\hline $\begin{array}{l}\text { Satisfazer as necessidades dos } \\
\text { clientes e ampliar as potenciali- } \\
\text { dades do negócio }\end{array}$ & $\begin{array}{l}\text { Resgatar pessoas da situação de } \\
\text { risco social e promovê-las }\end{array}$ \\
\hline
\end{tabular}

Fonte: Melo Neto, Froes (2002, p.11).

O empreendedor privado corre risco, inova, aproveita oportunidades para a geração de negócios lucrativos, formula estratégias para criar ou penetrar em novos mercados, escolhe bem os membros da equipe e tem visão a longo prazo. Para esses empresários, a medida do sucesso é o lucro, e, ao identificarem oportunidades de negócio, registram-nas como patente e marca, passando a considerá-las propriedade individual, sejam elas de natureza material ou intelectual.

Já o empreendedorismo social considera o impacto na sociedade como a medida de sucesso e o critério de avaliação do empreendimento é a diminuição dos problemas 
sociais, o número de pessoas beneficiadas com a proposta de trabalho implantada e a repercussão na melhoria da qualidade de vida de certa população. Segundo Melo Neto e Froes (2002, p. 9), os empreendedores sociais "são pessoas que trazem aos problemas sociais a mesma imaginação que os empreendedores do mundo dos negócios trazem à criação de riqueza".

As idéias de empreendedorismo social são pontuais, mas importantes no trato microssocial com os grupos comunitários. Já as diretrizes e estratégias de ação propostas pelos intelectuais da economia solidária são amplas: várias de cunho macrossocial, algumas com chances de se concretizarem em prazo menor, e outras em longo prazo, por envolverem mudança de orientação cultural. Em ambas as visões, a solidariedade se contrapõe à competição que explora e massifica a força de trabalho.

Em seguida, apresentaremos o resultado de nossas observações relativas ao contexto, conteúdo e dilemas das iniciativas voltadas para o empreendimento solidário, ocorridas em áreas de carência socioeconômica, com um tipo de grupo denominado "específico", por Mance (2006).

\section{Reflexões a partir da observação de grupos comunitários de base local voltados para a geração de trabalho e renda, de forma solidária}

1) Nas comunidades localizadas em áreas geográficas periféricas, surgem idéias empreendedoras que visam ao desenvolvimento de potencialidades, dons e habilidades dos moradores, à elevação da auto-estima e geração de trabalho e renda, além de contribuirem para a ocupação do tempo ocioso 
de pré-adolescentes, jovens e adultos. Portanto, são propostas voltadas para o bem-estar individual e coletivo de "grupos específicos" (Mance, 2006), e para superar a exclusão e a desesperança. São de natureza "protetora", porque se contrapõem aos fatores de risco social, passíveis de causar algum dano em termos de qualidade de vida (ver Pagnocelli \& Souza, 1987) .

2) Esses "grupos específicos" formam-se de diferentes maneiras: por iniciativa dos moradores e das pastorais sociais religiosas ou incentivados por programas sociais governamentais e ONGs. Alguns começam com objetivo apenas socializante de troca de conhecimentos e vivências, mas, aos poucos, vislumbram a possibilidade de se aprender uma atividade que, posteriormente, gere renda. Outros grupos definem, já no início, o aspecto da produção e a meta de se formar uma cooperativa.

3) São grupos "abertos" de base local, pois não há uma seleção prévia para as pessoas deles participarem. A nucleação do grupo se dá pelo interesse de se estar presente naquele espaço, para ali conviver com outras pessoas, fazer algo construtivo e fugir do isolamento, da ociosidade e da depressão. Por isso, o grupo acolhe uma heterogeneidade de participantes. As "mães" vão acompanhadas por suas crianças pequenas e os adolescentes e jovens levam seus amigos e vizinhos. Além das diferenças de idade e escolaridade, nem todos apresentam a mesma habilidade para confeccionar certo objeto ou para lidar com certo tipo de material. Algumas pessoas são pacientes, persistentes, concentramse com facilidade e executam trabalhos minuciosos 
e delicados; outras pessoas são mais dispersas e agitadas.

4) Os participantes definem qual tarefa consideram mais adequada - artesanato, trabalho manual ou outra atividade envolvendo tecido, miçangas, pedrarias, linhas, lã, barbante, sementes, papel, tinta, etc. - e as pessoas se agregam em torno daquela idéia. Alguns optam por reciclar, reutilizar, reaproveitar objetos; outros preferem comprar a matéria-prima básica já preparada nas lojas especializadas em artesanato. A primeira idéia, colocada em prática, pode ser modificada em face das dificuldades enfrentadas na confecção do produto, na obtenção da matéria-prima, no custo final ou na comercialização. Costuma ocorrer uma fase de experimentação, de tentativas e erros, e, posteriormente, o grupo ou participante faz opção por um ou mais produtos. Encontramos verdadeiros artistas, pessoas muito criativas, habilidosas com determinado tipo de material, e arredias frente a outro material. Por isso, é conveniente ao grupo maior fracionar-se em subgrupos, que optam por um tipo de trabalho e cada pessoa escolhe em qual deles quer ficar.

5) Com o tempo, forma-se um núcleo interno de membros constantes, persistentes e capazes, e "uma borda" constituída por membros que entram, saem e retornam. O grupo, paulatinamente promove a capacitação e passa a eleger e adotar padrões de desempenho e de qualidade. Em vista do progresso alcançado na confecção de determinado trabalho, surge o debate sobre se fechar um determinado subgrupo avançado e manter subgrupos iniciantes. Acontece também a convivência, no mesmo espaço, 
de pessoas mais e menos capacitadas, as primeiras auxiliando as demais, desde que haja um mínimo de habilidade potencial para o trabalho em foco.

6) Várias situações são vivenciadas para a obtenção de um produto de boa qualidade, como: pesquisar o material que possibilite um melhor resultado e refazer o trabalho mal feito. O grupo precisa ser orientado sobre a relevância de se observar, testar, comparar, repetir a tarefa certo número de vezes, se necessário. $O$ imediatismo não é o melhor caminho a ser seguido e não se pode esperar um produto "bom" da primeira vez em que é feito. A persistência e humildade, o reconhecimento do erro e a esperança de que se pode melhorar são qualidades favoráveis ao espírito empreendedor. Dificultam-no, entretanto, a onipotência, o orgulho, a vaidade, a racionalização e outros mecanismos psicológicos que aparecem nos grupos. Geralmente, somos muito susceptíveis a críticas, mas não há como fugir da seguinte realidade: se o produto não ficou bonito, não teve harmonia e não ficou bem acabado, ninguém irá comprá-lo. Essas considerações, se por um lado precisam ser feitas, por outro, não podem contribuir para abaixar a auto-estima, às vezes, já diminuída.

7) Na fase inicial da aprendizagem, é necessário haver maior diretividade por parte do professor-artesão, para se evitar desperdício de matéria-prima. Costuma haver uma criatividade dispersa e descontrolada, um fazer pelo fazer, sem se pensar em um trabalho planejado, o que irá redundar em produtos de má qualidade, a serem descartados. Participantes mais jeitosos para o trabalho manual e outras atividades, logo adquirem o domínio da tarefa e, nesse caso, ficam mais autônomos. 
8) Vários estudos sobre empreendedorismo destacam a "personalidade empreendedora" como fruto do meio ambiente em que a pessoa vive, da educação recebida e das experiências vivenciadas em negócios familiares ou profissionais (ver Mineiro \& Leite, 2003). Há uma carência da "cultura empreendedora" nos grupos comunitários, a ser superada por meio de orientações pedagógicas que enfatizem o pensar, a persistência e a independência, a flexibilidade e a resistência a frustrações, o dinamismo e a habilidade de relacionamentos (ver Bernardi, 2003).

9) Em algumas comunidades, o acesso das pessoas a estímulos que favorecem a imaginação e a criatividade é precário. Surge, também, o fato de os participantes não terem experiência referente à combinação de cores, nem domínio de como realizar o acabamento com capricho ou executar e compor detalhes dos produtos Por isso, é importante que o grupo comunitário organize excursões a lojas e a exposições de artesanato, leve para os encontros revistas, modelos e exemplares de produtos. A presença de pessoas experientes favorece, sobremaneira, encontrar saídas para resolver esses impasses e para refletir e criar com aquilo que se tem em mãos.

10) Os participantes costumam continuar em casa os trabalhos iniciados em grupo. Para tanto, necessitam de ferramentas e de materiais apropriados. Nem todos têm condição de adquirir objetos como, por exemplo, tesoura de boa qualidade para cortar tecido, revólver de cola quente, pincéis, etc. É conveniente a distribuição de kit de material para os que, realmente, farão bom uso dele.

11) Comumente, deparamo-nos com uma visão simplista em relação ao artesanato. Segundo esta 
visão, qualquer pessoa, ferramenta ou maquinário poderiam ser adequados ao objeto a ser produzido. Não se deve menosprezar a importância, neste campo de ação, do conhecimento especializado do professor de artesanato e de trabalho manual, do apoio profissional do designer, das ferramentas e maquinários específicos, da habilidade, vocação e gosto dos aprendizes.

12) Os grupos procuram descobrir recursos humanos, materiais e de comercialização dentro e fora do bairro. Pessoas conhecidas adquirem o produto finalizado, mas há necessidade de se procurar feiras, lojas e compradores em outras regiões. O momento da precificação e comercialização requer cálculos, discussões e orientação especializada. É momento de aprendizagem e, também, de entendimento da sociedade na qual estamos inseridos.

13) Vencida a etapa de domínio na confecção do produto, pode-se pensar em trilhar o caminho da formação de uma cooperativa. Não é por "passe de mágica" que os grupos comunitários adquirem condição de formar uma cooperativa de produtores. Nesses grupos comunitários, não se trabalha, no primeiro momento, com produtores, mas, com aprendizes.

14) Importante ressaltar que o mérito dos grupos comunitários não está focado, apenas, na possibilidade de formação de cooperativas. Como esses grupos acolhem uma heterogeneidade de pessoas, serão também diferenciados os resultados da ação. Os conhecimentos e as vivências obtidas no grupo poderão favorecer o trabalho autônomo de alguns, o emprego formal de outros, a volta à escola e a participação em outros grupos internos ou externos à comunidade. 
15) É importante que a Senaes, ou outra entidade, ofereça apoio financeiros aos grupos comunitários para pagar professores/artesãos e materiais iniciais de aprendizagem. Passado algum tempo, o próprio grupo reserva uma porcentagem para assumir certas despesas. O apoio financeiro não deve ocorrer desvinculado do apoio pedagógico ao artesão, para se evitar desperdício de esforços e material. Há necessidade de orientações a respeito dos princípios da economia solidária, do cooperativismo e também sobre como integrar grupos ou pessoas já capacitadas e residentes em diferentes regiões geográficas, para trocar idéias ou montar trabalho conjunto. Ao haver a integração de grupos, por meio de fóruns e outras formas organizativas, como propõe a Senaes, seria possível a junção de artesãos especializados em determinados produtos, para formar cooperativas.

16) A metodologia de trabalho seguida no acompanhamento dos grupos pelos docentes e discentes da PUC-Minas, no período já citado, envolveu: 1) momentos de trabalhos manuais e confecção de artesanato; 2) momentos previamente preparados para debates de assuntos ligados à saúde, cidadania, violência, meio ambiente, família, participação comunitária, empreendedorismo, entre outros. Essa abordagem mais ampla possibilitou incluir pessoas nas dimensões do ser, estar, fazer, criar e saber. Foi possível, inclusive, certo ganho financeiro. 


\section{Conclusão}

Propostas para minimizar os impactos da crise do desemprego surgem tanto em nível microssocial-comunidades - como em nível macrossocial. É importante que as duas dimensões se completem.

Nos grupos de base local das áreas periféricas há potencial promissor para se gerar trabalho e renda, e, assim, capaz minimizar situações de exclusão, desde que haja o acompanhamento especializado do professor/artesão e dos profissionais vinculados à política de economia solidária.

Acreditamos que a formação de cooperativas depende de haver, em primeiro lugar, domínio na confecção do produto e, posteriormente, capacitação e apoio sobre empreendimentos solidários.

\section{Referências}

AMARO, Rogério Roque. A exclusão social hoje. Cadernos do Instituto São Tomaz de Aquino (ISTA), Lisboa, v. 5, n. 9, 2000. Disponível em <http://www. triplov.com/ista/cadernos/cad_09/amaro.html>. Acesso em: 20 jun. 2007.

BERNARDI, Luiz Antonio. Manual de empreendedorismo e gestão. São Paulo: Atlas, 2003.

BRASIL. MINISTÉRIO DO DESENVOLVIMENTO SOCIAL E COMBATE À FOME (MSD). Guia de ações para a geração de trabalho e renda constantes do orçamento fiscal da união. Governo Federal. Versão 1.0 - 10 de abril de 2007.

DUPAS, Gilberto. As várias dimensões da exclusão social e da pobreza. In: . Economia global e exclusão social: pobreza, emprego, estado e o futuro do capitalismo. 3. ed. São Paulo: Paz e Terra, 2001.

MANCE, Euclides. Políticas públicas para o desenvolvimento econômicosolidário do Brasil. In: CONFERÊNCIA NACIONAL DE ECONOMIA SOLIDÁRIA. 2006, Brasília. [Anais da 1a…]. Brasília: MTE, 2006. 
MELO NETO, Francisco Paula; FROES, César. Empreendedorismo social: a transição para a sociedade sustentável. Rio de Janeiro: Qualitymark , 2002.

MINEIRO, Andréia Aparecida da Costa; LEITE, Valéria Fonseca. Educação empreendedora e sua contribuição para o sucesso ou fracasso do empreendedor. In: CONGRESSO NACIONAL DE EMPREENDEDORISMO. 2003. [Anais do 1…]: a competência empreendedora do gestor globalizado. Florianópolis (SC): PFP e associados, 2003.

SINGER, Paul. A Economia Solidária como ato pedagógico. In: KRUPPA, Sonia M. Portella (org.). Economia Solidária e educação de jovens e adultos. Brasília: Inep, 2005. p. 13-20.

SOUZA, Pagnoncelli Ronald; EISENSTEIN, Evelyn. Situações de risco à saúde de crianças e adolescentes. Rio de Janeiro: Vozes, 1987. 